Original Article

\title{
MEASUREMENT OF CORTISOL AND CORTISONE IN HUMAN SALIVA BY UPLC-MS/MS
}

\author{
SYED N. ALVI' ${ }^{1}$, MUHAMMAD M. HAMMAMI²
}

${ }^{1}$ Clinical Studies and Empirical Ethics Department, King Faisal Specialist Hospital and Research Center, P 0 Box \# 3354, MBC-03, Riyadh 11211, Saudi Arabia, ${ }^{2}$ Centre for Genomics Medicine Department, King Faisal Specialist Hospital and Research, Center, P 0 Box \# 3354, MBC-03, Riyadh 11211, Saudi Arabia

Email: salvi@kfshrc.edu.sa

Received: 17 Apr 2021, Revised and Accepted: 08 Jun 2021

ABSTRACT

Objective: To develop and validate a simple and rapid assay for simultaneous measurement of cortisol and cortisone in human saliva by ultraperformance liquid chromatography-tandem mass spectrometry.

Methods: Chromatographic analysis was performed on an Atlantis dC18 column $(2.1 \mathrm{x} 100 \mathrm{~mm}, 3 \mu \mathrm{m})$ using a mobile phase consisting of acetonitrile and $2 \mathrm{mmol}$ ammonium-acetate $(50: 50, \mathrm{v}$; v) that was delivered at a flow rate of $0.3 \mathrm{ml} / \mathrm{min}$. The eluents were monitored using electrospray ionization in the positive ion mode set at transition set of mass-to-charge (m/z): $363.11 \rightarrow 121.00,361.18 \rightarrow 163.11$, and $367.19 \rightarrow$ 121.24 for cortisol, cortisone and internal standard (IS), respectively the method was validated for linearity, accuracy, precision, and recovery, according to international guidelines.

Results: The retention times of cortisol, cortisone and internal were about 1.38, 1.43 and $1.38 \mathrm{~min}$, respectively. Cortisol level and cortisone level relationship to the ratio of their respective peak-area to IS's peak-area was linear (range of $0.5-100 \mathrm{ng} / \mathrm{ml}$ ). Coefficients of variation and inaccuracy were, $\leq 9.9 \%$ and -0.3 to 6.9 for cortisol and 8.4 and -1.5 to 4.8 for cortisone, respectively. Extraction recoveries for cortisol, cortisone, and the IS were $90 \%, 94 \%$, and $98 \%$, respectively. Cortisol and cortisone stability was evaluated in processed saliva samples (stored at room temperature for $24 \mathrm{~h}$ ) and unprocessed saliva samples (stored at room temperature for $24 \mathrm{~h}$ or at- $20^{\circ} \mathrm{C}$ for $10 \mathrm{w}$ ) and after 3 freeze-thaw cycles was $\geq 86 \%$.

Conclusion: The proposed method is simple, precise, and accurate for the rapid simultaneous measurement of cortisol and cortisone levels in saliva. The assay was successfully applied to determine levels of cortisol and cortisone in human saliva samples obtained from healthy volunteers

Keywords: Cortisol, Cortisone, Cortisol-d4, Saliva, UPLC-MS/MS

(C) 2021 The Authors. Published by Innovare Academic Sciences Pvt Ltd. This is an open access article under the CC BY license (https://creativecommons.org/licenses/by/4.0/) DOI: https://dx.doi.org/10.22159/ijpps.2021v13i8.41829. Journal homepage: https://innovareacademics.in/journals/index.php/ijpps.

\section{INTRODUCTION}

Cortisol, a steroid hormone secreted by the adrenal cortex, has an important function in metabolism, electrolyte balance, and the immune response, among others [1,2]. Estimation of cortisol and cortisone in the saliva is used in evaluating the adrenal axis as it reflects that biologically active cortisol and sample assortment is not related to stress $[3,4]$. Since cortisol is metabolized to cortisone (biologically inactive) by the salivary glands, via 11-ßhydroxysteroid dehydrogenase type-2 (11ß-HSD2), an assay that can simultaneously measure cortisol and cortisone would allow better assessment of the adrenal axis and is essential for studying the salivary gland $11 ß-H S D 2$ activity $[5,6]$.

Several assays for determining cortisol and cortisone levels in saliva and other biological fluids are reported [7-16]. Generally, commercially available kits are used for monitoring cortisol and cortisone levels by enzyme immunoassay and chemiluminescence individually $[7,8]$. Whereas, high-performance-liquidchromatography (HPLC) equipped with ultraviolet [9] or fluorescence [10] detector or tandem-mass-spectrometry (LCMS/MS) [11-15] were used for simultaneous measurement of cortisol and cortisone levels in human plasma [11], serum [12] urine [13] and saliva [14, 15]. For Bioanalysis, often derivatizers [14] or expensive solid-phase extraction cartridges $[13,15]$ are utilized in sample preparation.

We report a simple, ultra-performance liquid chromatographytandem mass spectrometry (UPLC-MS/MS) method for simultaneous measurement of cortisol and cortisone levels in saliva, utilizing liquid-liquid extraction and cortisol-d4 as an internal standard (IS). The method was validated by following United States FDA guidelines [19] and it was utilized to monitor cortisol and cortisone levels in human saliva.

\section{MATERIALS AND METHODS}

\section{Chemicals and solvents}

We obtained cortisol (hydrocortisone) and cortisone from Acros organic NJ, USA, and cortisol-d4 from Sigma-Aldrich MO, USA. We purchased potassium phosphate (monobasic), sodium phosphate (dibasic), potassium chloride, sodium chloride, ammonium acetate, methyl-tert-butyl-ether, hexane (all AR grade) and acetonitrile (HPLC grade) from Fisher Scientific, NJ. USA. We prepared Milli-Q water by passing purified water through the Milli-Q System (Millipore, Bedford, MA, USA). The study was approved by the Research-Ethics-Committee, King Faisal Specialist Hospital and Research Centre, Riyadh (2191297).

\section{Equipment and analytical conditions}

Ultra-performance-liquid-chromatograph (UPLC) integrated solvent and sample manager (Acquity) equipped with tandem mass spectrometer (MS/MS) Xevo-TQD and an interface of Z-spray atmospheric pressure ionization (API) (Waters Corporation, Milford, MA, USA) were utilized for analysis. Analytes were estimated using an Atlantis dC18 steel column that was protected by an in-line filter. We used a mobile phase of $0.002 \mathrm{M}$ ammonium-acetate and acetonitrile (50:50, v: v) that was passed through Supor membrane filter (Pall Gelman Laboratory, MI, USA) before delivery $(0.3 \mathrm{ml} / \mathrm{min})$. We operated the electrospray-ionization-source operated in the positiveion-mode (capillary voltage $1.50 \mathrm{kV}$, cone voltage 35 volts). Nitrogen for nebulization/desolvation $(1000 \mathrm{~L} / \mathrm{h})$ and argon for collision $(3.6 \mathrm{x}$ $10^{-3} \mathrm{mbar}$ ) were used. We found the optimum collision energy of $20 \mathrm{eV}$ for cortisol, cortisone, and the IS. Ion source and desolvation temperatures were maintained at $150{ }^{\circ} \mathrm{C}$ and $500{ }^{\circ} \mathrm{C}$, respectively. Cortisol, cortisone, and IS were detected in positive-ion-mode utilizing multiple-reaction-monitoring (MRM) at the transition of mass-tocharge $(\mathrm{m} / \mathrm{z})$ of: $363.11 \rightarrow 121.00,361.18 \rightarrow 163.111$, and $367.19 \rightarrow$ 121.24 for cortisol, cortisone, and IS, respectively. 


\section{Standard and control samples}

We prepared cortisol, cortisone, and IS solutions in $1.0 \mu \mathrm{g} / \mathrm{ml}$ methanol. We prepared 9 standards $(0.5-100 \mathrm{ng} / \mathrm{ml})$ and 4 qualitycontrol solutions $(0.5,1.5,50$ and $90 \mathrm{ng} / \mathrm{ml})$ in phosphate buffered saline (combination of $0.01 \mathrm{M}$ sodium phosphate, $0.0018 \mathrm{M}$ potassium phosphate, $0.137 \mathrm{M}$ sodium chloride and $0.0027 \mathrm{M}$ potassium chloride, $\mathrm{pH}=7.4$, adjusted with $\mathrm{HCl}$ ).

To validate the utilization of calibration standards in phosphatebuffered saline, about $230 \mathrm{ml}$ human saliva was collected and levels of cortisol and cortisone were measured at baseline (blank). Four quality controls were prepared by spiking cortisol and cortisone in blank saliva at $0.5,1.5,50$, and $90 \mathrm{ng} / \mathrm{ml}$. Differences in levels of cortisol and cortisone between blank saliva and spiked saliva (as read against the calibration standards) were compared to the expected increase in level from the amount that were spiked. The differences were-0.03,$1.14,1.77$, and $5.28 \mathrm{ng} / \mathrm{ml}$ for cortisol and $-0.01,0.11,-0.31,2.82 \mathrm{ng} / \mathrm{ml}$ for cortisone for four concentrations, respectively. We prepared an IS's solution $(100 \mathrm{ng} / \mathrm{ml})$ in methanol. All solutions were stored at $4{ }^{\circ} \mathrm{C}$ and used within four weeks of preparation.

\section{Saliva sample collection}

We collected unstimulated saliva by direct spitting in sterile tubes that were stored at $-20^{\circ} \mathrm{C}$ until analyzed.

\section{Sample preparation}

We added $200 \mu \mathrm{l} \mathrm{IS's} \mathrm{the} \mathrm{solution}(100 \mathrm{ng} / \mathrm{ml})$ to $1.0 \mathrm{ml}$ unknown, standard, or quality control samples that were then vortexed for 30 seconds. We added four ml combination of methyl-tert-butyl-ether and hexane $(8: 2, \mathrm{v}: \mathrm{v})$, vortexed the mixture for $2 \mathrm{~min}$, and then centrifuged it (4000 rpm) for $10 \mathrm{~min}$ at $20^{\circ} \mathrm{C}$. We collected the clear supernatant layer collected and dried it under a nitrogen stream $\left(40{ }^{\circ} \mathrm{C}\right)$. We reconstituted the residue in methanol $(100 \mu \mathrm{l})$ and analyzed $10 \mu \mathrm{l}$.

\section{Recovery}

We examined cortisol, cortisone, and IS extraction recovery by comparing peak-areas of extracted and un-extracted samples (five replicates, $0.5,1.5,50$ and $90 \mathrm{ng} / \mathrm{ml}$ ) for cortisol and cortisone. Similarly, IS recovery was determined at $100 \mathrm{ng} / \mathrm{ml}$.

\section{Stability}

Five aliquots of 2 QC concentrations (1.5 and $90 \mathrm{ng} / \mathrm{ml}$ ) were analyzed without storage (baseline), 5 aliquots were kept at room temperature $24 \mathrm{~h}$ before analysis, 5 were kept in- $20^{\circ} \mathrm{C}$ for $10 \mathrm{w}$ before analysis, and 5 were kept at room temperature for $24 \mathrm{~h}$ after processing and before analysis. Finally, 15 aliquots were kept at -20 ${ }^{\circ} \mathrm{C}$ for $24 \mathrm{~h}$ before thawing at room temperature, 5 aliquots were analyzed and 10 returned to- $20^{\circ} \mathrm{C}$ for $24 \mathrm{~h}$. This was repeated 3 times.

\section{Matrix-effect}

We studied the matrix-effect by contrasting peak-areas of cortisol and cortisone $(0.5,1.5,50$, and $90 \mathrm{ng} / \mathrm{ml})$ and $I S(100 \mathrm{ng} / \mathrm{ml})$ in spiked-after-extraction samples with the corresponding peak-areas of standards in methanol.

\section{Assay-validation}

We validated the assay according to the guidelines of the United States FDA [16].

\section{Collection of saliva from healthy volunteers}

We collected $2-3 \mathrm{ml}$ saliva samples by direct spitting in the morning (7-9 AM) and kept on $-20^{\circ} \mathrm{C}$.

\section{RESULTS}

\section{Separation and quantification}

We determined the product and precursor ions of cortisol, cortisone, and cortisone-d4 (IS) by infusing a standard mixture containing cortisol, cortisone, and cortisol-d4 in the mass-spectrometer. We used a configured software program (Intellistart, Waters Corporation, Milford, MA, USA). Fig. 1 depicts the MS/MS spectrum and chemical structures of these compounds. The best liquidchromatographic conditions were obtained with a mobile phase of 2 mmol ammonium-acetate and acetonitrile (50:50, v: v) with a flow rate $0.3 \mathrm{ml} / \mathrm{min}$. The mass-spectrometry acquisition was achieved with multiple-reaction-monitoring in positive-ion mode. Cortisol, cortisone, and IS retention times were around 1.38, 1.43, and 1.38 min, respectively.

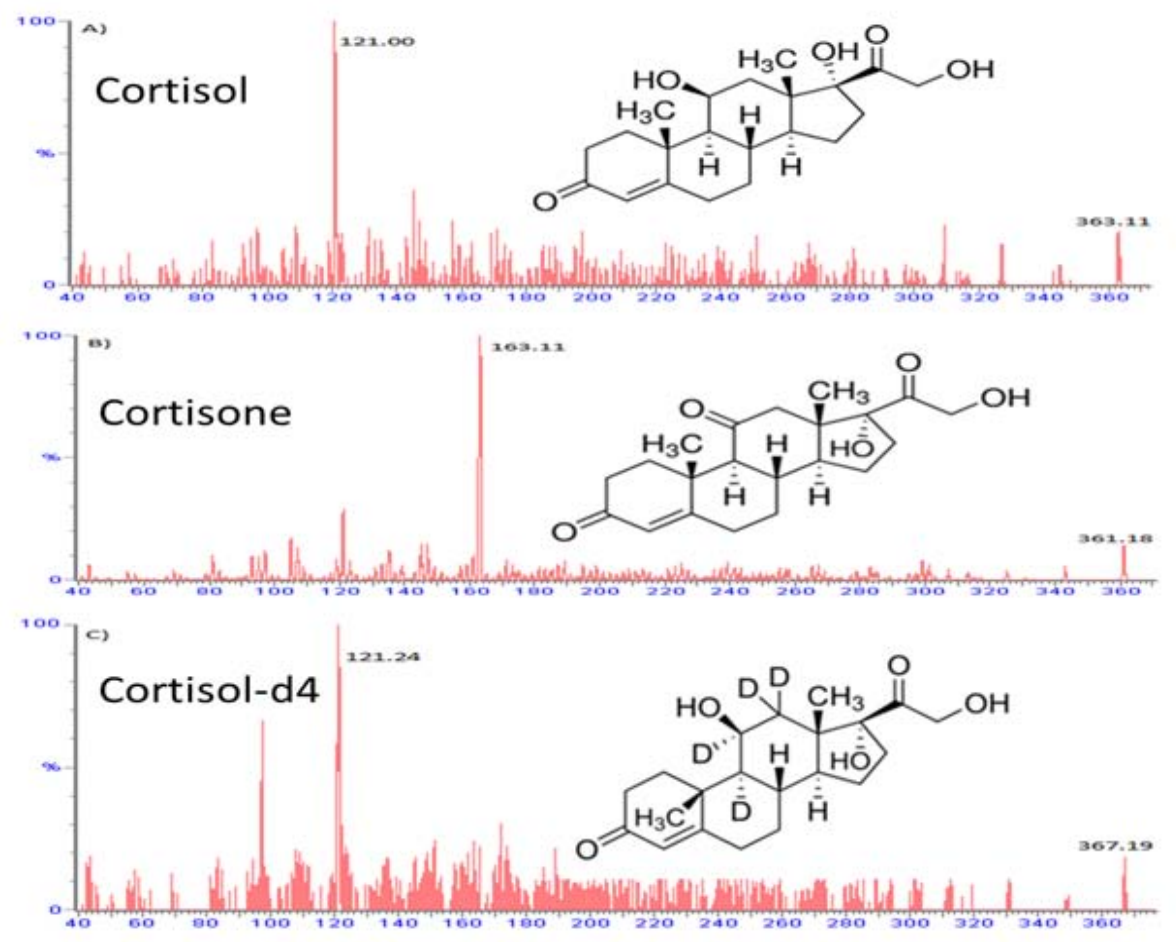

Fig. 1: MS/MS spectrum and chemical structures of cortisol, cortisone, and cortisol-d4 (internal standard) 


\section{Matrix-effect}

Mean-matrix effect (at $0.5,1.5,50$ and $90 \mathrm{ng} / \mathrm{ml}$ ) was measured as ion suppression,-4.5\%,-2.6\%, and-3.6\% for cortisol, cortisone and IS, respectively.

\section{Specificity}

We evaluated specificity by analyzing 6 batches of blank human saliva and 7 cortisol-related compounds, namely, cortisone, progesterone, $17 \alpha$-hydroxyprogesterone, prednisone, prednisolone, methylprednisone and testosterone. The solutions were prepared as $1.0 \mu \mathrm{g} / \mathrm{ml}$ in methanol: water $(1: 1, \mathrm{v}: \mathrm{v}) .10 \mu \mathrm{l}$ were injected. No interference with analytes' peaks was observed. Fig. 2 shows chromatograms of human saliva samples used to prepare quality controls.

\section{Recovery}

Mean extraction recoveries of cortisol and cortisone $(0.5,1.5,50$ and $90 \mathrm{ng} / \mathrm{ml}, 5$ aliquots each) were 90\%, and 94\%, respectively. Recovery of IS (100 ng/ml) was $98 \%$.
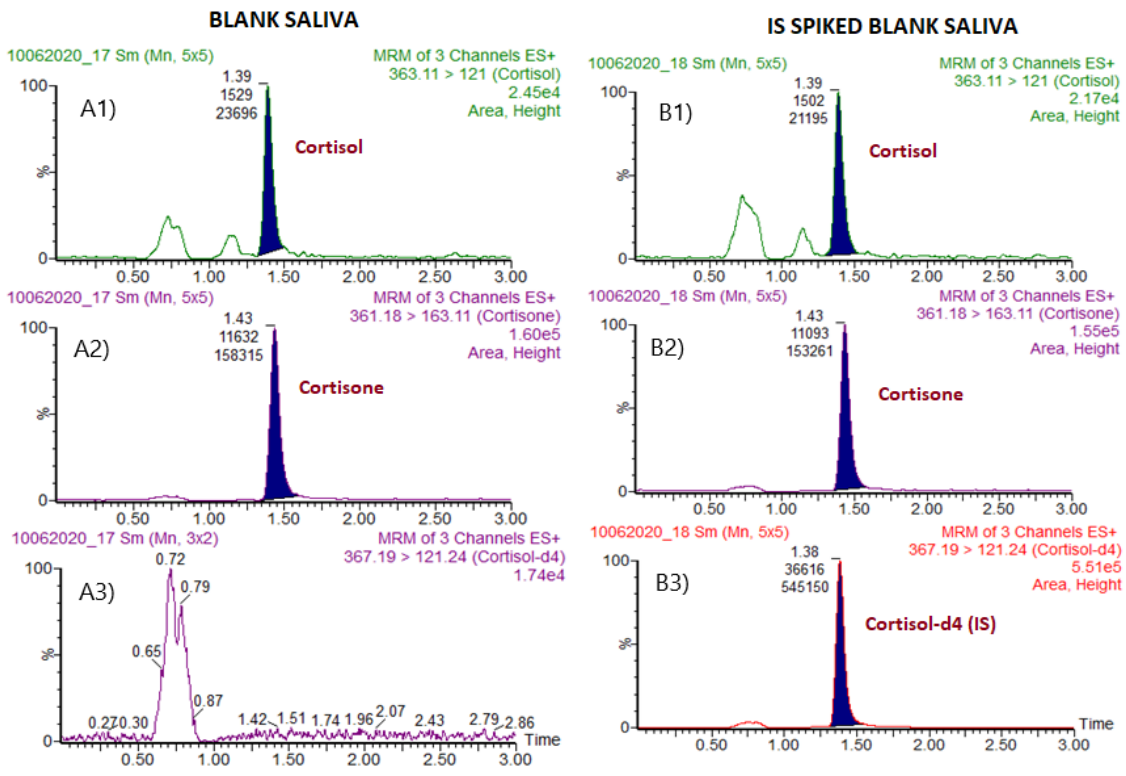

Fig. 2: Chromatogram of multiple-reaction-monitoring of human saliva used to prepare quality controls. Blank saliva (A1-A3). Blank saliva spiked with internal standard (B1-B3)

\section{Linearity, detection limit, and quantification limit}

We evaluated assay linearity by analyzing standard mixtures containing cortisol and cortisone in phosphate buffered saline at 9 different concentrations $(0.5-100 \mathrm{ng} / \mathrm{ml})$. Corresponding peak-area ratios and concentrations were analyzed by regression analysis Mean $(n=8)$ equations were $y=0.0531 x-0.0218, r^{2}=0.9991$ for cortisol and $y=0.0454 x-0.0163, r^{2}=0.9989$ for cortisone. Limits of detection and quantification (for both cortisol and cortisone) were $0.3 \mathrm{ng} / \mathrm{ml}$ and $0.5 \mathrm{ng} / \mathrm{ml}$, respectively.

\section{Precision and inaccuracy}

Intra-day and inter-day precision and inaccuracy were assessed for four quality control samples $(0.5,1.5,50$, and $90 \mathrm{ng} / \mathrm{ml})$. Intra-day $(n=10)$ coefficients of variation $(\mathrm{CV})$ and inaccuracy ranged from $2.8 \%$ to $9.8 \%$ and $-1.0 \%$ to $9.7 \%$, for cortisol and from $4.0 \%$ to $7.9 \%$ and $-1.0 \%$ to $6.2 \%$ for cortisone, respectively. Inter-day (n=20) CV and inaccuracy ranged from $5.5 \%$ to $9.9 \%$ and- $0.3 \%$ to $6.9 \%$ for cortisol, and from $5.2 \%$ to $8.4 \%$ and $-1.5 \%$ to $4.8 \%$ for cortisone, respectively (table 1).

Table 1: Intra-day and inter-day precision and inaccuracy of cortisol and cortisone assays

\begin{tabular}{|c|c|c|c|c|c|c|}
\hline \multirow{2}{*}{$\begin{array}{l}\text { Nominal level } \\
\text { (ng/ml) }\end{array}$} & \multicolumn{3}{|l|}{ Intra-day $(n=10)$} & \multicolumn{3}{|l|}{ Inter-day $(n=20)$} \\
\hline & Mean (SD) measured level & CV (\%) & Bias (\%) & Mean (SD) measured level & CV (\%) & Bias (\%) \\
\hline \multicolumn{7}{|l|}{ Cortisol } \\
\hline 0.5 & $0.49(0.05)$ & 9.8 & -1.0 & $0.50(0.05)$ & 9.9 & -0.3 \\
\hline 1.5 & $1.65(0.05)$ & 2.8 & 9.7 & $1.60(0.09)$ & 5.5 & 6.9 \\
\hline 50 & $52.19(2.30)$ & 4.4 & 4.4 & $50.3192 .88)$ & 5.7 & 0.6 \\
\hline 90 & $93.24(3.98)$ & 4.3 & 3.6 & $89.83(5.61)$ & 6.3 & -0.2 \\
\hline \multicolumn{7}{|l|}{ Cortisone } \\
\hline 0.5 & $0.50(0.04)$ & 7.9 & -1.0 & $0.49(0.05)$ & 8.4 & -1.5 \\
\hline 1.5 & $1.59(0.10)$ & 6.5 & 6.2 & $1.56(0.11)$ & 7.2 & 3.9 \\
\hline 50 & $49.93(3.53)$ & 7.1 & -0.1 & $52.13(3.86)$ & 7.4 & 4.3 \\
\hline 90 & $92.27(3.73)$ & 4.0 & 2.5 & $94.34(4.86)$ & 5.2 & 4.8 \\
\hline
\end{tabular}

$\mathrm{SD}$ is the standard deviation. $\mathrm{CV}$ is the coefficient of variation $(\mathrm{SD} /$ mean measured level multiplied by 100$)$. Inaccuracy= measured level-nominal level/nominal level multiplied by 100 .

\section{Stability}

We assessed the stability of cortisol and cortisone under common laboratory conditions. Little or no change in concentration was observed. (Table 2) In processed saliva samples, cortisol and cortisone were stable at room temperature for $24 \mathrm{~h} \mathrm{(} \geq 91 \%$ ). In unprocessed saliva samples, they were stable for $24 \mathrm{~h}$ at room temperature $86 \%), 10 \mathrm{w}$ at $-20^{\circ} \mathrm{C}(\geq 88 \%)$, and after 3 freeze-thaw cycles ( $\left.\geq 89 \%\right)$. 
Table 2: Stability of cortisol and cortisone in various laboratory conditions

\begin{tabular}{|c|c|c|c|c|c|c|c|}
\hline & \multicolumn{2}{|l|}{ Processed } & \multicolumn{2}{|c|}{ Unprocessed } & \multicolumn{3}{|c|}{ Freeze and thaw } \\
\hline & Zero time & $24 \mathrm{~h}$ (RT) & 24 h (RT) & 10 wks $\left(-20^{\circ} \mathrm{C}\right)$ & Cycle-1 & Cycle-2 & Cycle-3 \\
\hline Cortisol & 1.55 & 1.41 & 1.33 & 1.36 & 1.29 & 1.38 & 1.46 \\
\hline Level ng/ml, (SD) & $(0.09)$ & $(0.07)$ & $(0.14)$ & $(0.04)$ & $(0.06)$ & $(0.09)$ & $(0.07)$ \\
\hline \multirow[t]{4}{*}{ Stability (\%) } & & (91) & $(86)$ & (88) & (83) & (89) & (94) \\
\hline & 95.27 & 91.44 & 89.50 & 85.51 & 86.93 & 92.57 & 83.85 \\
\hline & $(1.98)$ & $(1.98)$ & (1.13) & $(2.09)$ & $(1.83)$ & $(1.54)$ & $(0.78)$ \\
\hline & & (96) & (94) & (90) & (112) & (97) & (88) \\
\hline Cortisone & 1.42 & 1.53 & 1.55 & 1.36 & $1.59(0.06)$ & $1.33(0.11)$ & $1.27(0.13)$ \\
\hline Concentration & $(0.12)$ & $(0.09)$ & $(0.08)$ & $(0.04)$ & $(112)$ & (94) & (89) \\
\hline $\mathrm{ng} / \mathrm{ml},(\mathrm{SD})$ & & (108) & (109) & $(96)$ & & & \\
\hline \multirow[t]{3}{*}{ Stability (\%) } & 90.94 & 94.67 & 99.67 & 85.51 & 93.60 & 82.99 & 84.87 \\
\hline & $(2.45)$ & $(4.62)$ & (2.89) & (2.09) & $(5.00)$ & $(3.06)$ & $(1.00)$ \\
\hline & & $(104)$ & (110) & $(94)$ & (103) & (91) & (93) \\
\hline
\end{tabular}

RT indicates room temperature, hr indicates hours, wks indicates weeks, FT indicates Freeze-Thaw. Stability (\%) equals average measured level $(n=5)$ at specified time/average measured level $(n=5)$ at baseline $x 100$.



Fig. 3: Multiple-reaction-monitoring chromatogram of saliva sample collected from healthy volunteer spiked with IS (20 ng). Measured level of A) Cortisol (2.4 ng/ml) B) Cortisone (26.7 ng/ml) and C) Cortisol-d4 (IS)

\section{Application of the method}

The validated assay was used to determine the level of cortisol and cortisone in saliva samples collected from healthy volunteers. Fig. 3 depicts a typical chromatogram of saliva sample that represents measured levels of cortisol and cortisone were $2.4 \mathrm{ng} / \mathrm{ml}$ and 26.7 $\mathrm{ng} / \mathrm{ml}$, respectively.

\section{DISCUSSION}

Analysis of human saliva is a non-invasive and inexpensive test that can serve as a source of valuable information for diagnosis of several hormonal diseases including cushing's and nephrotic syndrome in adult and children $[17,18]$. The measurement of cortisol in saliva reflects the free and biologically active fraction of cortisol in plasma/serum. Due to the auto-conversion process, cortisol metabolized to cortisone (biologically inactive) by the salivary glands, via 11-ß-hydroxysteroid dehydrogenase type-2 (11ß-HSD2) [5-6]. Therefore, presences of cortisol and cortisone in saliva are always expected. The measurement of cortisol and cortisone levels in saliva provides a more comprehensive picture of the adrenal axis function than the measurement of cortisol alone. Further, the measurement also essential for studying 11-ß-hydroxysteroid dehydrogenase type-2 activity in salivary glands. Usually, immunoassay techniques were used for measurements cortisol and cortisone in biological fluid. However, the technique often suffer the issue of interferences due to cross-reactivity with structurally related substances. In order to avoid the cross-reactive, Vieira et al. reported a liquid chromatography-tandem mass spectrometry method for simultaneous measurement of cortisol and cortisone in saliva by adopting the procedure that involves derivatization with hydroxylamine [14]. Whereas, Allende F, et al. and Jones RL, et al., used solid-phase extraction procedure utilizing commercially available disposable cartridges in sample preparation $[13,15]$. In comparison to these reported methods, we described here a simple and rapid method for simultaneous measurement of cortisol and cortisone, using a liquid-liquid extraction procedure that does not require expensive reagents or disposable cartridges. The recovery of all analytes was measured more than $90 \%$, precision and inaccuracy of the method were than $10 \%$, respectively.

\section{CONCLUSION}

A validated UPLC-MS/MS assay for simultaneous measurement of cortisol and cortisone levels in human saliva is reported. The assay is based on liquid-liquid extraction and use of cortisol-d4 as an 
internal standard. The assay was used to determine the stability of cortisol and cortisone under common laboratory conditions and was applied in determining cortisol and cortisone levels in the saliva of healthy volunteers.

\section{FUNDING}

Nil

\section{AUTHORS CONTRIBUTIONS}

Dr. Syed N Alvi: Performed experiments, analyzed data and drafted manuscript.

Dr. Muhammad M Hammami: Critically reviewed data and revised manuscript.

\section{CONFLICTS OF INTERESTS}

Declared none

\section{REFERENCES}

1. Bauer ME. Chronic stress and immunosenescence: a review. Neuroimmunomodulation 2008;15:241-50.

2. Saiah E. The role of 11 beta-hydroxysteroid dehydrogenase in metabolic disease and therapeutic potential of 11 beta-HSD1 inhibitors. Curr Med Chem 2008;15:642-9.

3. Restituto P, Galofre JC, Gil MJ, Mugueta C, Santos S, Monreal JI, et al. Advantage of salivary cortisol measurements in the diagnosis of glucocorticoid related disorders. Clin Biochem 2008;41:688-92.

4. Castagnola M, Scarano E, Passali GC, Messana I, Cabras T, lavarone F, et al. Salivary biomarkers and proteomics: future diagnostic and clinical utilities. Acta Otorhinolaryngol Italica 2017;37:94-101.

5. Best R, Walker BR. Additional value of measurement of urinary cortisone and unconjugated cortisol metabolites in assessing the activity of 11 beta-hydroxysteroid dehydrogenases in invo. Clin Endocrinol (Oxf) 1997;47:231-6.

6. Ferrari P. The role of $11 ß$-hydroxysteroid dehydrogenase type-2 in human hypertension. Biochim Biophys Acta 2010;1802:1178-802

7. Gozansky WS, Lynn JS, Laudenslagert ML, Kohrt WM. Salivary cortisol determined by enzyme immunoassay is preferable to serum total cortisol for assessment of dynamic hypothalamicpituitary-adrenal axis activity. Clin Endocrinol 2005;63:336-41.
8. Corral PD, Schurman RC, Kinza SS, Fitzgerald MJ, Kordick CA, Rusch JL, et al. Salivary but not plasma cortisone tracks the plasma cortisol response to exercise: effect of time of day. J Endocrinol Invest 2016;39:315-22

9. Palo EF De, Antonelli G, Benetazzo A, Prearo AM, Gatti R. Human saliva cortisone and cortisol simultaneous analysis using reverse phase HPLC technique. Clin Chim Acta 2009;405:60-5.

10. Glowka FK, Kosicka K, Karazniewicz Kada M. HPLC method for determination of fluorescence derivatives of cortisol, cortisone and their tetrahyrdro-and allo-tetrahydro-metabolities in biological fluids. J Chrom B Anal Tech Biomed Life Sci 2010;87:283-9.

11. Sosvorova L, Vitku J, Chlupacova T, Mohapl M, Hampl R Determination of seven selected neuro-and immunomodulatory steroids in human cerebrospinal fluid and plasma using LC-MS/MS. Steroids 2015;98:1-8.

12. Lee S, Lim HS, Shin HJ, Kim SA, Park J, Kim HC, et al. Simultaneous determination of cortisol and cortisone from human serum by liquid chromatography-tandem mass spectrometry. J Anal Methods Chem 2014. DOI:10.1155/2014/787483

13. Allende F, Solari S, Campino C, Carvajal CA, Lagos CF, Vecchiola A, et al. LC-MS-/MS method for simultaneous determination of free Urinary steroids. Chromatographia 2014;77:637-42.

14. Vieira JG, Nakamura $\mathrm{OH}$, Carvalho VM. Determination of cortisol and cortisone in human saliva by a liquid chromatography-tandem mass spectrometry method. Arq Bras Endocrinol Metab 2014;58:844-50.

15. Jones RL, Owen JL, Adaway JE, Keevil BG. Simultaneous analysis of cortisol and cortisone ibn saliva using XLC-MS/MS for fully automated online solid-phase extraction. J Chrom B Anal Tech Biomed Life Sci 2012;15:42-8.

16. Alvi SN, Hammami MH. Measurement of cortisol in human plasma and urine by ultra-performance liquid chromatography-tandem mass spectrometry. Asian J Pharm Clin Res 2018;11:199-203.

17. Khairani A, Fauziah E, Budiardjo SB. Relationship between oral health-related quality of life and salivary cortisol levels in children with caries. Int J Appl Pharm 2017;9:125-7.

18. Wijayanti DNN, Zairina N, Asmaningsih N, Yulistiani. Analysis of cortisol level after high-dose and long-term prednisone exposure in children with steroid-sensitive nephrotic syndrome. Asian J Pharm Clin Res 2018;3Suppl:56-60.

19. "Bioanalytical Method Validation" Guidance for Industry US Department of Health Services, Food and Drug Administration, CDER, CVM; 2018. 